\title{
Wacker verdoppelt in China Dispersionskapazitäten
}

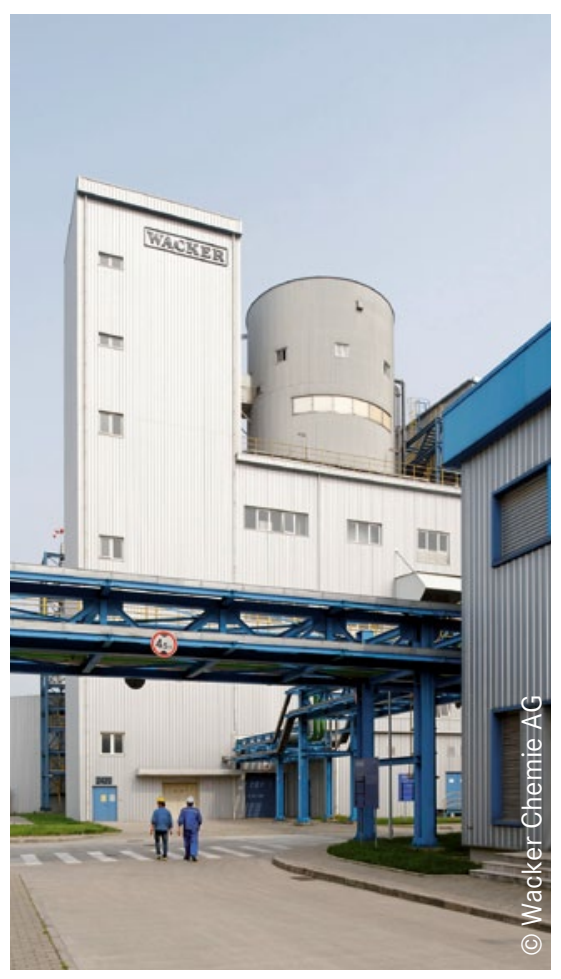

Am vollintegrierten Wacker-Produktionsstandort in Nanjing werden Dispersionen und Dispersionspulver hergestellt, die als Bindemittel unter anderem in der Bau-, Beschichtungs- und Klebstoffindustrie Verwendung finden.
W acker hat am Standort Nanjing in China (Provinz Jiangsu) eine neue Produktionsanlage für Vinylacetat-Ethylen-Copolymer (VAE)-Dispersionen offiziell in Betrieb genommen. Mit den zusätzlichen 60.000 Tonnen aus der zweiten Reaktorlinie verdoppelt sich die Kapazität an VAE-Dispersionen vor Ort auf insgesamt 120.000 Jahrestonnen.

Der Anlagenkomplex ist damit einer der größten seiner Art in China. Gleichzeitig errichtet der Konzern im Werk Nanjing derzeit eine neue Anlage zur Herstellung von Polyvinylacetat (PVAc)-Festharzen mit einer Jahreskapazität von 20.000 Tonnen. Die Inbetriebnahme dieser Anlage ist für Ende 2013 geplant. Die Investitionen für beide Projekte belaufen sich insgesamt auf rund 40 Mio. €.

Wacker trägt mit dem Ausbau seiner Dispersionsanlage dem steigenden Bedarf an hochwertigen VAE-Dispersionen Rechnung, insbesondere in China und den Schwellenländern Südostasiens. Ziel der Investitionsmaßnahme ist es, auch in Zukunft ausreichende Ka- pazitäten für die starke Nachfrage nach VAE-Dispersionen der Marke Vinnapas bereitzustellen und so den Kunden in der Region langfristig gleichbleibende Produkt- und Liefersicherheit zu gewährleisten.

Bereits im Februar hatte Wacker am Standort Ulsan in Korea eine neue VAE-Produktionsanlage mit weiteren 40.000 Jahrestonnen in Betrieb genommen. Dazu Rudolf Staudigl, Vorsitzender des Vorstands der Wacker Chemie AG:,Mit dem Ausbau in Korea und China verdoppeln wir unsere VAE-Kapazitäten in der Region und festigen so unsere weltweit führende Stellung in diesem Bereich.“

An dem voll integrierten Produktionsstandort im Nanjing Chemical Industrial Park stellt Wacker bereits VAE-Dispersionen und Dispersionspulver für die Bau-, Beschichtungs- und Klebstoffindustrie her. Die zusätzlichen Kapazitäten aus der zweiten Anlage sollen zudem das starke Wachstum in den Bereichen Farben, Papier-, Teppichund Vliesstoffanwendungen sicher begleiten.

\section{Motek und Bondexpo auf Wachstumskurs}

G ut fünf Monate vor Start der Messen Motek und Bondexpo am 7. Oktober meldet der Messeveranstalter Schall eine Ausstellerzahl von deutlich über 800. Zur 32. Motek - Internationale Fachmesse für Produktions- und Montageautomatisierung haben bereits ca. 700 Unternehmen und zur 7. Bondexpo - Internationale Fachmesse für Klebtechnologie 100 fest gebucht. Beachtenswert sei die jedes Jahr zunehmende Anzahl an Automations-Systemhäusern und Robotertechnik-Systemintegratoren sowie Herstellern von Montageanlagen und Komplettlösungen. Darüber hinaus fächere sich das Angebot an Handhabungstechnik und Robotik, Materialfluss- und Fördertechnik sowie an Füge- und Verbindungstechnik weiter auf. Für die Kunden und Anwender - egal ob Hersteller von Vorrichtungen, Teilsystemen und Komplettanlagen oder produzierender Endkunde - biete dies den entscheidenden Vorteil, sich über alle relevanten $\mathrm{Au}$ tomatisierungs-Bausteine, so auch über schlüsselfertige Komplettlösungen im Detail und als Ganzes, informieren zu können.

Weitere Infos: www.bondexpo-messe.de

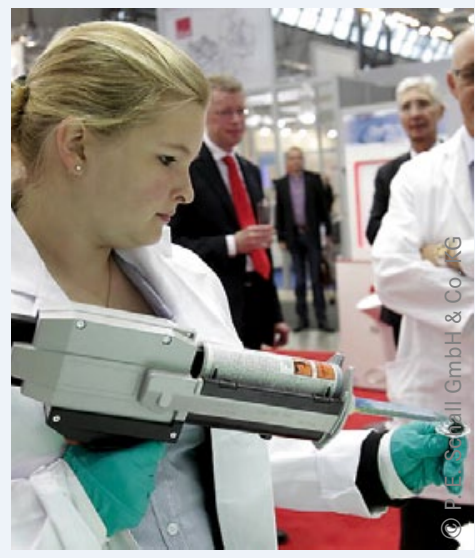

Messeimpression Bondexpo 2012 